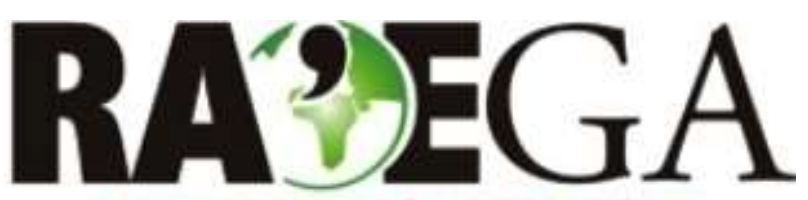

O ESPACO GEOGRÁFICO EM ANÁLISE

\title{
GEOSSISTEMAS EM AMBIENTES MONTANHOSOS: A REVELAÇÃO DA PAISAGEM NA SERRA DO CAPARAÓ (MG/ES)
}

\section{GEOSYSTEMS IN MOUNTAINOUS ENVIRONMENTS: THE REVEALING OF THE LANDSCAPE IN SERRA DO CAPARAÓ (MG/ES)}

\author{
Roberto Marques Neto \\ Professor Adjunto do Departamento de Geociências e do Programa \\ de Pós-graduação em Geografia \\ Universidade Federal de Juiz de Fora - UFJF \\ Juiz de Fora, MG, Brasil \\ e-mail: roberto.marques@uffif.edu.br \\ Geovane Caon de Oliveira \\ Universidade Federal de Juiz de Fora - UFJF \\ Juiz de Fora, MG, Brasil \\ e-mail: geovanecaon@hotmail.com \\ Johnny Souza Dias \\ Universidade Federal de Juiz de Fora - UFJF \\ Juiz de Fora, MG, Brasil \\ e-mail: Johnnys.dias@hotmail.com
}

Recebido em: 29/10/2015

Aceito em:04/04/2016

\section{Resumo}

Em ambientes montanhosos a estrutura e dinâmica dos geoambientes é fortemente controlada pela altitude, posto que se formata uma sucessão altitudinal de microclimas, das fitofisionomias e dos sistemas de transformação pedológica, fazendo com que a influência do relevo na definição dos geossistemas ocorrentes seja das mais significativas, interpenetrando elementos azonais ao controle forjado pela zonalidade climática. A partir de tais premissas, o presente artigo tem por objetivo apresentar os resultados logrados a partir do estudo dos geossistemas existentes na Serra do Caparaó (MG/ES), interpretados e mapeados segundo a integridade inerente aos grupos de fácies, e cujos resultados corroboraram os pressupostos iniciais. Foram interpretados doze grupos de fácies que se integram em três classes de fácies 
que engendram o indivíduo geográfico discernido no maciço do Caparaó, que se adéqua, no plano hierárquico dos geossistemas, na condição de um topogeócoro. As classes de fácies interpretadas, e que congregam os doze grupos de fácies, foram as seguintes: Patamares de cimeira com campos herbáceos e arbustivos; Escarpas e patamares florestados com campos; Degraus e patamares reafeiçoados com rampas coluviais. Os resultados levaram à conclusão central acerca da expressiva influência do relevo na definição de unidades geossistêmicas em compartimentos geomorfológicos de gênese tectônica e submetidos a forte controle tectônico e estrutural ao longo de sua evolução morfológica. No caso específico do maciço do Caparaó, as unidades integrais concretas expressas no grupo de fácies se revelaram adequadas, articulando de forma contundente aspectos evolutivos e dinâmicos de relevância para a gestão e planejamento da paisagem.

Palavras-chave: Abordagem geossistêmica; Maciço do Caparaó; indivíduo geográfico; grupos de fácies.

Abstract
In mountainous environments the structure and dynamics of the geoenvironments is tightly controlled by height since an altitudinal succession of micro-weathers, phytophysiognomies and pedological transformation systems is formatted making the influence of the relief in the definition of the occurring geosystems become one of the most significant interpenetrating azonal elements to the control forged by the climatic zonality. From these premises the present article aims on presenting the results obtained on the studies of the geosystems existing in Serra do Caparaó (MG/ES) interpreted and mapped according to the integrity inherent to the groups of facies and which results corroborate the initial presuppositions. From these premises the present article aims on presenting the results obtained on the studies of the geosystems existing in Serra do Caparaó (MG/ES) interpreted and mapped according to the integrity inherent to the groups of facies and which results corroborate the initial presuppositions. Twelve groups of facies which integrate three classes of facies that engender the geographic individual discerned in the massive of Caparaó that is adapted, in the hierarchic plain of the geosystems, in the condition of a topogeocore were interpreted. The classes of facies interpreted and which congregate the twelve groups of facies were the following: Summit plateaus with herbaceous and shrubby fields; Scarps and plateaus forested with fields; Reshaped steps and plateaus with colluvial ramps. The results took us to the central conclusion about the expressive influence of the relief in the definition of geosystemic unities in geomorphological compartments of tectonic genesis and submitted to strong tectonic and structural control along its morphological evolution. In the specific case of the massive of Caparaó the concrete integral unities expressed in the group of facies were revealed adequate articulating in a 
contundent way evolutive and dynamic aspects of relevance to the landscape management and planning.

Key-words: Geosystemic approach; Caparaó Massif; geographic individual; groups of facies.

\section{INTRODUÇÃO}

A formação da cultura geomorfológica e geográfica brasileira, fortemente apegada ao sistema francófono de pensamento, firmou um entendimento acerca da evolução do relevo brasileiro a partir de uma concepção majoritariamente climática que teria engendrado diferentes ciclos erosivos responsáveis pela formação de superfícies de aplainamento distintas, concepção esta que encontrou um sólido aporte nos trabalhos de De Martonne (1943) e, doravante, nos estudos de King (1956), cimentados pela Teoria da Pediplanação, que impôs em nosso meio científico uma decisiva ruptura epistemológica com o modelo davisiano. A ideia do aplainamento praticamente onipresente, atacando indiscriminadamente diferentes estruturas geológicas, conduziu, por sua vez, a uma ideia debilitada, embora perseverante na época, de que o relevo brasileiro era cronologicamente senil, invocando ainda um ranço davisiano em sua interpretação geral. A ideia de um relevo "antigo", produto de um longo tempo de erosão que obliterou divisores de águas e rebaixou sobremaneira diferentes conjuntos de formas, foi encarnada com veemência no ensino, tirando até mesmo proveito do apelo didático da Teoria do Ciclo Geográfico de Willian Morris Davis. Concomitantemente, a concepção de relevos policíclicos de Emanuel De Martonne constava acessoriamente na interpretação da evolução do relevo a partir da ideia de rejuvenescimento, como consta, por exemplo, em Azevedo (1949).

A forte influência de Lester King e sua concepção acerca dos ciclos de aplainamento foram itens influentes no estabelecimento de um paradigma climático na geomorfologia brasileira (VITTE, 2011), bem como de uma nomenclatura para o nosso relevo, que chegou a evitar classificar um relevo montanhoso pelo fato do autor reconhecer essa tipicidade morfológica apenas em cinturões orogenéticos, ficando como herança dessa concepção a 
viciosidade em se considerar uma montanha apenas em situações nas quais as altitudes superassem 3000 metros. Faria (2005) frisa que o critério fundamental para se definir um relevo montanhoso não é a altitude acima do nível do mar, mas sim sua altura em relação aos compartimentos geomorfológicos com os quais estabelece contato, e que deve ser superior a 300 metros de amplitude, endossando a proposição de Price (1981). Tal reflexão é relevante na classificação de uma série de compartimentos geomorfológicos brasileiros de origem tectônica, uma vez que relevos tectônicos são normalmente caracterizados por seu aspecto montanhoso, com grandes amplitudes, declividades acentuadas e um padrão de entalhe vertical em profundidade com densidade de drenagem tendencialmente alta em função da também alta densidade de linhas de fraqueza. No Brasil, portanto, embora não ocorram cordilheiras e cinturões orogênicos ativos, existem montanhas tectonicamente geradas, como as Serras do Mar, da Mantiqueira, do Espinhaço, etc., ou mesmo residuais de aplainamento que estabelecem contatos abruptos com compartimentos depressionários em consideráveis desníveis. Acerca dessa problemática, a resolução metodológica de Ponçano et al. (1981) para o mapeamento geomorfológico do estado de São Paulo firma uma proposta de relevo montanhoso invocando os desníveis superiores a 300 metros associados a declives predominantes maiores que $15 \%$ na definição dessas geoformas.

As elevações imperiosas e as significativas amplitudes altimétricas que caracterizam os relevos montanhosos engendram sucessões altitudinais de geoabientes, uma vez que variam com a altitude os sistemas de transformação pedológica, os grupos fitofisionômicos e florísticos e as condições microclimáticas. Hugget (1995), sobre isso, discute as diferentes zonas de vegetação, solos e gradientes climáticos altitudinais que se consubstanciam ao longo de uma montanha e a influência de tais fatores na fauna, posto que também fica estabelecida uma tendência de sucessão de habitats a partir da base das escarpas montanhosas em demanda às cumeeiras.

O presente trabalho se firma, portanto, na premissa de que em paisagens montanhosas, de gênese tectônica, o relevo é o atributo mais 
influente na definição de unidades geossistêmicas, que se organizam escalonadamente em um padrão geral de sucessão altitudinal em resposta à variação nos fatores ambientais impostos pela altitude. A partir de tais premissas e tomando como agente cimentante os pressupostos teóricometodológicos desenvolvidos no âmbito da geografia eslava a partir das proposições de Sochava $(1971,1978)$, divulgar-se-á no corpo deste paper os resultados referentes à interpretação, classificação e mapeamento dos geossistemas na Serra do Caparaó, importante indivíduo geográfico pertencente ao compartimento da Mantiqueira Setentrional (sensu RADAMBRASIL, 1983), posicionado na divisa entre os estados de Minas Gerais e Espírito Santo.

\section{MATERIAIS E MÉTODOS}

A proposição conceitual de geossistema, que embasa o presente trabalho, emergiu na antiga União Soviética e foi propugnada por Viktor B. Sochava nos primeiros anos da década de 1960, tendo sido divulgada pelo geógrafo eslavo em diversas publicações (SOCHAVA, 1971, 1977, 1978, 1978a). Por conceito, o geossistema é um sistema ou uma integridade natural que se consubstancia em diferentes escalas têmporo-espaciais e que estabelece conexões com a esfera socioeconômica, e as informações geográficas podem ser organizadas em um sistema bilateral que congrega integridades espaciais homogêneas (geômeros) e heterogêneas (geócoros), sendo os geócoros os indivíduos geográficos e os geômeros os tipos de paisagem existentes.

Pelo princípio do agrupamento e da hierarquização, os geossistemas se organizam em três grandes níveis escalares (topológicos, regionais e planetários) que, por sua vez, se subdividem em várias subcategorias, cada uma delas representando uma unidade espacial concreta discernível na escala em questão. Dessa forma, conforme elucidado por Sochava $(1977,1978)$, as áreas homogêneas elementares se unem em fácies, que por sua vez formam grupos de fácies e, em um nível hierárquico superior, as classes de fácies, cujo agrupamento engendra os geômeros, unidade tipológica que marca a 
passagem das grandezas topológicas para as regionais. Na fileira oposta, dos geócoros, têm-se os correspondentes níveis hierárquicos organizados em geócoros elementares, micro, meso, topo e macrogeócoros, e daí para as organizações regionais e planetárias. O geossistema, portanto, se organiza dos níveis locais mais elementares (fácies físico-geográficas) até as grandes unidades terrestres e o próprio sistema Terra (envelope geográfico).

A grandeza sub-regional da Serra do Caparaó exigiu que sua interpretação se desse em níveis escalares topológicos não elementares, tendo sido adotada a escala de 1/50.000 para interpretação e mapeamento. A unidade tipológica de representação foi o grupo de fácies, intermediária nos níveis topológicos, formadas a partir do agrupamento de áreas homogêneas elementares e fácies (figura 1), arranjadas em unidades superiores (grupos e classes de fácies) pelo princípio da hierarquização. Em conformidade ao frisado por Haase (1989), as unidades espaciais geocóricas resultam da combinação das unidades tipológicas, bem como do seu arranjo no espaço.

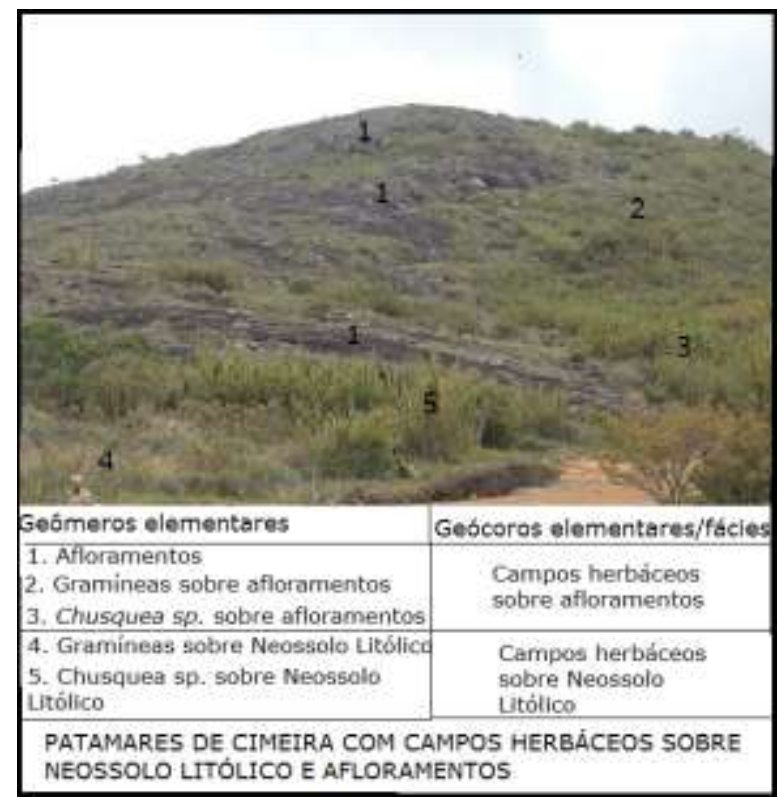

Figura 1. Esquema de hierarquização na interpretação dos grupos de fácies a partir de geômeros elementares.

As unidades geossistêmicas foram definidas a partir da correlação entre o relevo, os grupos fitofisionômicos, os principais sistemas de transformação pedológica e o uso da terra, adotando-se esta sequência para a organização 
da legenda. Subsequentemente os geossistemas foram agrupados segundo 0 predomínio de elementos zonais e azonais em sua composição, conforme a concepção metodológica de Isachenko (1973), abordagem interessante na interpretação da paisagem em regiões montanhosas de pronunciado escalonamento vertical. Considerando que a sucessão altitudinal dos geoambientes é dada normalmente por contatos transicionais e não truncados, foram diferenciados dois tipos de limites, difusos e abruptos, o que melhora o discernimento acerca da natureza das faixas de contato entre as unidades, muitas vezes dadas por áreas de tensão ecológica de largura variável. Ainda, a partir das colocações de Rodriguez et al. (2010), as unidades mapeadas foram diferenciadas em seus aspectos estruturais segundo o predomínio de estruturas naturais, antroponaturais e antropogênicas, o que permite melhor visualização do grau de transformação da paisagem.

A compartimentação geomorfológica da Serra do Caparaó foi levada a efeito com base no escalonamento topográfico a partir das rupturas de declive marcadas nas folhas topográficas na escala de 1/50.000 (Divino de São Lourenço - SF-24-V-A-IV-2, lúna - SF-24-V-A-I-4, Espera Feliz - SF-24-V-A-IV1, Manhumirim - SF-24-V-A-I-3) e com o auxílio de imagens de radar SRTM (Shuttle Radar Topography Mission) em relevo sombreado imageado em quatro ângulos azimutais de iluminação $\left(45^{\circ}, 90^{\circ}, 315^{\circ}\right.$ e $\left.360^{\circ}\right)$. Foram então discernidas diferentes unidades topomorfológicas (patamares de cimeira, escarpas dissecadas, degraus reafeiçoados, etc.), em conformidade à proposta apresentada por Cunha e Mendes (2005). A técnica em questão foi adotada em função de sua proficiência em representar compartimentos de relevo definidos com a sucessão de patamares altimétricos escalonados, arranjo este verificado na Serra do Caparaó. Para tanto, foi necessário reconhecer os padrões de declive marcados nas isolinhas e na carta clinográfica, gerada em software ArcGIS, que também subsidiou o procedimento de compartimentação, levado a efeito no ambiente ArcMap.

Para a interpretação das coberturas superficiais foram empreendidos transectos ao longo das vias de acesso, pelas quais foram estabelecidas diferentes topossequências para caracterização e coleta de amostras de 
materiais pedogeneizados, submetidos à análise química (fertilidade e matéria orgânica) e granulométrica, levadas a efeito no Laboratório de Solos da Universidade Federal de Lavras. As dificuldades de acesso dadas pela declividade, vegetação extensiva e poucas trilhas são compensadas por certa homogeneidade litológica, geomorfológica e de padrões de drenagem, o que facilita a replicação dos tipos encontrados no sentido topo-base para os setores inacessíveis, procedimento que também buscou apoio na interpretação das folhas topográficas e imagens de satélite.

O mapeamento do uso da terra e cobertura vegetal também lançou mão do software ArcGIS, optando-se por utilizar a extensão ArcBrutile versão 0.3.3 (Bing Maps), anexada no ambiente do ArcMap (ESRI®), possibilitando assim a manipulação de imagens fornecidas pelo programa mediante significativa precisão. A técnica em questão consiste, basicamente, na criação de um shapefile de polígono, pelo qual as áreas das diferentes modalidades de uso e cobertura são contornadas por digitalização manual, e as informações são subsequentemente inseridas em uma tabela de atributos. Embora mais trabalhoso, tal procedimento possibilita a obtenção de um documento cartográfico mais detalhado e preciso em comparação às técnicas convencionais de classificação por máxima verossimilhança. As formações florestais foram classificadas segundo a proposta do IBGE (1992), e as formações campestres foram dissociadas segundo um caráter herbáceo, de resposta espectral mais lisa dada pelo estrato graminoso intercalado a afloramentos, e uma índole arbustiva, com aumento na rugosidade textural dada pelo maior adensamento lenhoso.

A correlação das informações em ambiente digital para geração do mapa de geossistemas também foi levada a efeito no ambiente ArcMap, que possibilitou a sobreposição das variáveis elementares na edição de um mapa regional-tipológico (ABALAKOV e SEDYKH, 2010) para o maciço do Caparaó.

\section{A INDIVIDUALIDADE GEOGRÁFICA DO CAPARAÓ}


A identidade regional do Caparaó (figura 2) é partilhada, de forma não muito articulada, por mineiros e capixabas, os primeiros ladeados à vertente oeste e os segundos à vertente leste da serra homônima, identidade esta fundamentalmente referenciada na cafeicultura. Um senso regional também se desenvolve em torno da atividade turística vinculada à presença do parque, referenciada no conjunto de lugares que praticam o turismo, e que tem na Serra do Caparaó e na unidade de conservação nela contida (Parque Nacional do Caparaó) sua principal imagem turística.

A Serra do Caparaó figura como imponente horst cujas proeminências se aproximam de 2.900 metros de altitude no Pico da Bandeira. Algumas dezenas de quilômetros a oeste posiciona-se outro alinhamento positivo dado pela Serra do Brigadeiro, e, entre os alinhamentos, o gráben de Carangola, compartimento rebaixado por efeitos tectônicos e erosivos, levado a efeito pela dissecação do rio Carangola e seus afluentes. A Serra do Caparaó em específico constitui uma imponente crista de direção geral N-S formada por falhamentos vinculados à própria formação da Serra da Mantiqueira no contexto do rift continental do sudeste brasileiro de Riccomini (1989), estabelecendo amplitudes altimétricas de quase 2000 metros com os compartimentos de morros convexos adjacentes ao maciço. De acordo com Novo et al. (2011), a base geológica na qual o maciço do Caparaó encontra-se emoldurado é dada pelos gnaisses-granulíticos e migmatitos ortoderivados da Suíte Caparaó, de idade paleoproterozoica (riaciana).

A decomposição das litologias granitoides que balizam o maciço do Caparaó engendram coberturas superficiais argilosas, ricas em caulinita, ainda que nos setores altimontanos o intemperismo físico seja mais contundente, com formação de tratos deposicionais locais com consideráveis quantidades de material clástico. Nesses geoambientes os solos são imaturos, predominando Neossolo Litólico associado ou não a Cambissolos. Nos patamares escalonados em escarpas e degraus predominam os Cambissolos em associação a Latossolos, além de alguma ocorrência de material com organização estrutural argilúvica, sendo que grande parte destes materiais 
encontram-se associados a depósitos de tálus e configuram colúvios pedogeneizados em um sistema geomorfológico de intenso retrabalhamento.

Ao longo do escalonamento da Serra do Caparaó pode ser reconhecido um padrão de sucessão altitudinal da vegetação em estreita relação com as diferenciações que se dão nos sistemas de transformação pedológica e no microclima. Pelos flancos escarpados encadeiam-se fisionomias de florestas ombrófilas, de caráter montano e alto-montano, que dão lugar aos campos nas altas escarpas e ao longo dos topos mais elevados. Como a maior parte da área está contida em uma unidade de conservação de proteção integral (Parque Nacional do Caparaó), estas fisionomias encontram-se preservadas. No entanto, transposto o perímetro da reserva, o cultivo do café se dá de forma maciça, intercalado a áreas de pastagem e práticas silviculturais.

A Serra do Caparaó estabelece acentuado contraste climático com as áreas adjacentes. Nas suas latitudes impera um clima tropical com temperaturas médias elevadas, com invernos moderados, tanto nos baixos terrenos do gráben de Carangola como nos patamares escalonados do Espírito Santo. No sopé do Caparaó em sua vertente mineira o município de Alto Caparaó se assenta entre 960 e 1000 metros acima do nível do mar, patamar altimétrico pelo qual se projeta um clima tropical de altitude com nítida queda das temperaturas médias, o que se intensifica nos altos cumes do maciço, onde os níveis térmicos são substancialmente mais baixos, as geadas são frequentes e a nebulosidade corriqueira. 


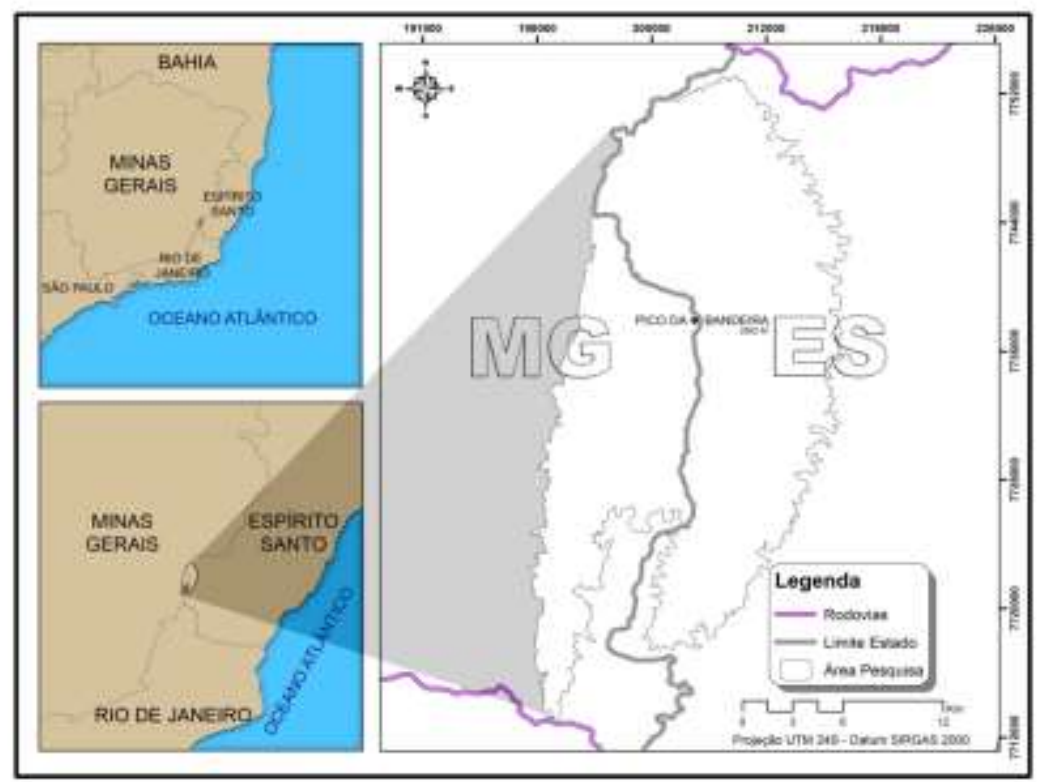

Figura 1. Localização da Serra do Caparaó.

\section{RESULTADOS E DISCUSSÃO}

Reconhecidamente, os ambientes montanhosos apresentam individualidade própria dada pelas peculiaridades que eclodem nesses enclaves emergentes. Rogerie (1990) assevera que, do ponto de vista ecológico, os três elementos mais importantes que sintetizam as singularidades dos meios montanhosos se referem aos fatores climáticos (temperatura, umidade, pressão), aos fatores edáficos (sistemas de transformação em geral menos desenvolvidos) e topográficos (altitudes e formas do relevo).

A individualização do maciço do Caparaó se consubstancia a partir de contato litológico bem marcado por falha que delimita os gnaisses e migmatitos da Suíte Caparaó (NOVO et al. 2011) de coberturas metassedimentares supracrustais neoproterozoicas. Formata-se assim, por si só, uma unidade morfoestrutural de contraste bem marcado com os sistemas geomorfológicos adjacentes, unidade esta caracterizada por vertiginosa elevação topográfica, sendo que as unidades de menor nível hierárquico se organizam em estreita relação com as influências engendradas pelo relevo. Os níveis topomorfológicos interpretados para a referida unidade morfoestrutural são representados na figura 2 , e, subsequentemente, a figura 3 permite 0 
estabelecimento de uma relação direta entre estes níveis e as unidades de uso e cobertura.

O alinhamento bem marcado na direção N-S que delimita a Serra do Caparaó define um sistema denudacional em forte controle estrutural, compartimentado em duas unidades topomorfológicas básicas. A mais elevada corresponde aos níveis superiores que avultam a partir de uma faixa altimétrica de 1500 metros, congregando os patamares de cimeira e as escarpas íngremes e preservadas como subunidades principais. Estabelece conexão bem marcada por rupturas de declive com um domínio de patamares escalonados caracterizados por maior retrabalhamento das vertentes em degraus e patamares que se sucedem em direção às morrarias adjacentes, com as quais o maciço do Caparaó estabelece contato por falha. Patamares mais baixos encontram-se reafeiçoados em interflúvios locais vinculados à drenagem paralela a subparalela que provem dos níveis superiores.

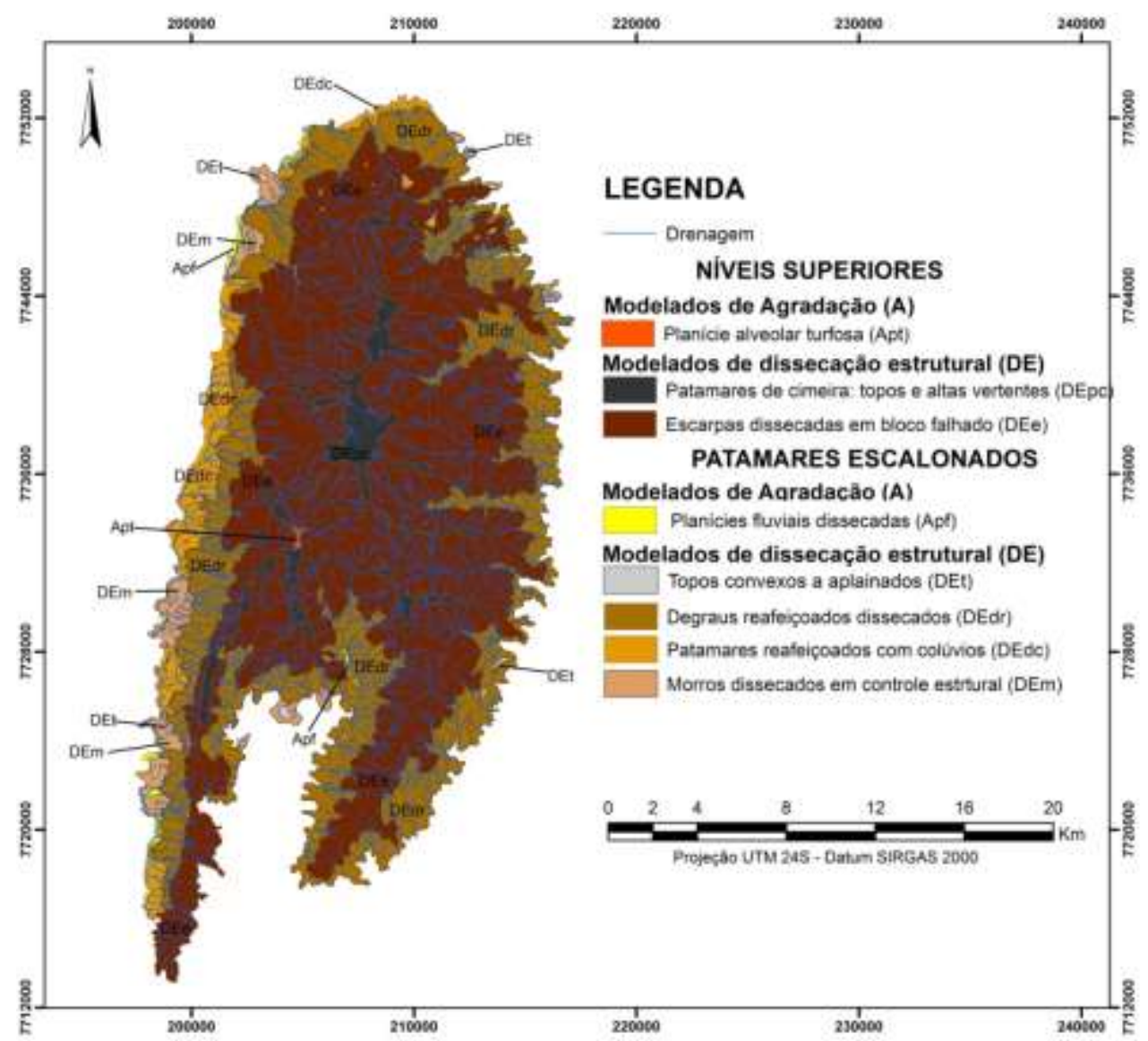

Figura 2. Unidades topomorfológicas da Serra do Caparaó. 


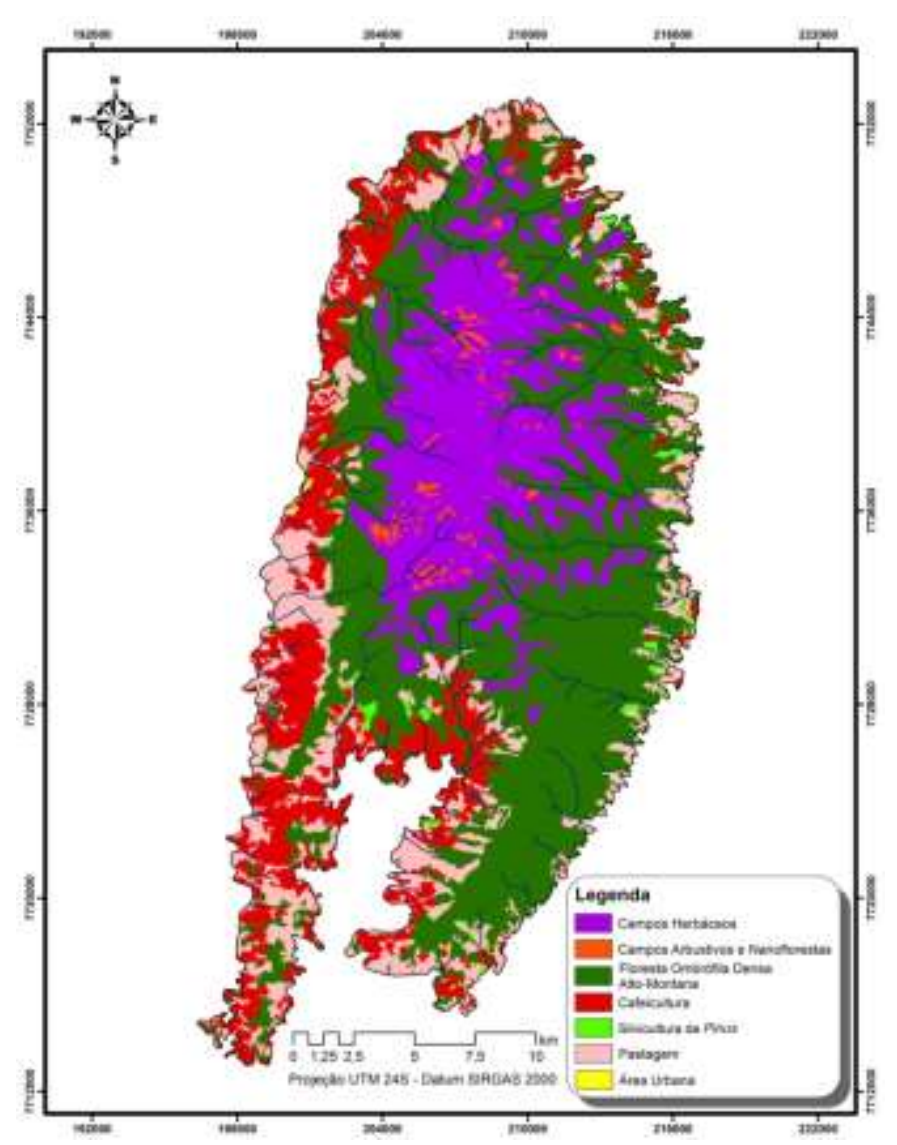

Figura 3. Cobertura vegetal e uso da terra no Maciço do Caparaó.

Enquanto indivíduo geográfico, o maciço do Caparaó avulta como um topogeócoro, ordem de grandeza sub-regional formada a partir da integração de doze mesogeócoros/grupos de fácies que, por sua vez, se unem em três classes de fácies. São estes tipos de paisagem que compõem a individualidade do maciço do Caparaó, que não chega a apresentar a expressão espacial macrogeocórica, tendo sua integridade melhor expressa em níveis escalares locais. A compartimentação geomorfológica influencia sobremaneira na definição das classes de fácies, definidas da seguinte forma: Patamares de cimeira com campos herbáceos e arbustivos; escarpas com campos e florestas; Degraus e patamares reafeiçoados com rampas coluviais. A figura 4 representa os grupos de fácies discernidos para o Caparaó, agrupados nas classes de fácies retrocitadas. As classes de fácies, por sua vez, conformam o 
topogeócoro dado pelo maciço, coadunando, no mesmo mapa, o indivíduo geográfico e os tipos de paisagem nele existentes.

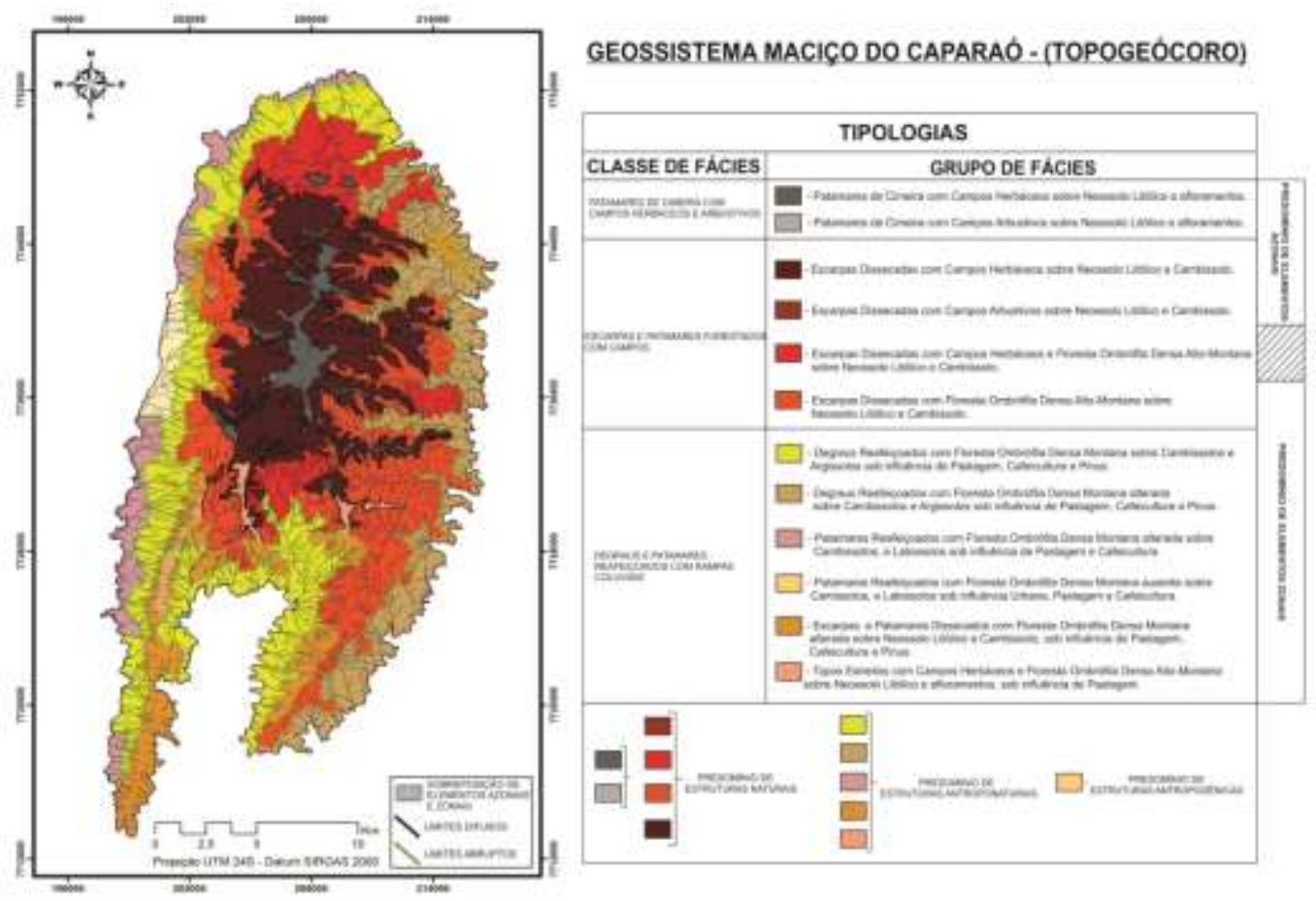

Figura 4. Geossistemas discernidos para a Serra do Caparaó.

Os patamares de cimeira correspondem aos somitais do maciço, que definem os topos e altas vertentes, onde os afloramentos são extensivos e a cobertura vegetal é dada por diferentes associações de campos herbáceos e arbustivos que medram sobre solos rasos ou apresentam índole rupestre. Os sistemas de transformação pedológica são dados por solos imaturos, fundamentalmente Neossolo Litólico, apresentando textura argilosa ligada enfaticamente à decomposição dos feldspatos que se apresentam em teores consideráveis nessas litologias. Em geral, comportam-se como zonas eluviais a transeluviais, projetando-se como áreas emissoras de fluxos de matéria e energia, transferindo a energia oriunda da atmosfera aos compartimentos adjacentes. Comportam pequenas áreas de acumulação em condição de enclave na forma de planícies alveolares turfosas com Organossolos, compartimentos estes que atuam como barreiras geoquímicas funcionais. 
A passagem dos patamares de cimeira para os compartimentos escarpados se dá por rupturas de declive bem marcadas, conforme pode ser constatado no mapa topomorfológico (figura 2), o qual deixa patente que a diferenciação destas duas classes de fácies se define com o contato das unidades topomorfológicas. A partir dos compartimentos escarpados o entalhe vertical se aprofunda perseguindo as linhas de fraqueza, os declives ficam pronunciados e o retrabalhamento se faz mais intenso. Os grupos de fácies que perfazem esta unidade comportam-se como zonas transmissoras dos fluxos de massa e energia, eminentemente transeluviais, com mobilização plena e constante de coberturas argilosas e de material detrítico de variadas dimensões. A partir de uma faixa altimétrica em torno de 1800 metros define-se uma zona de intolerância para a cobertura arbórea de caráter florestal, ainda que tal limite não seja fixo e responda a outras influências, como a orientação das vertentes e a iluminação e umidade desiguais associadas. A emergência de médias térmicas mais baixas e acentuação das amplitudes diárias acarreta diminuição da produtividade primária, o que, associado à presença de solos rasos e afloramentos, reduz a retenção hídrica. Paulatinamente, as florestas vão dando lugar aos campos (figura 5). Nas vertentes voltadas para leste, defronte ao avanço da massa tropical atlântica, e também naquelas orientadas para o sul, as florestas chegam a níveis altimétricos mais elevados, sobretudo ao longo dos segmentos côncavos mais úmidos vinculados ao trabalho de dissecação da drenagem projetada radial a paralelamente a partir das cimeiras, em altitudes recorrentemente superiores a 2000 metros. Nas vertentes posicionadas a sotavento, orientadas para o poente e para o norte, a faixa de emergência dos campos é mais baixa, em torno de 1500 metros de altitude.

Dessa forma, é no domínio das escarpas íngremes que se diferenciam geossistemas com predomínio de elementos zonais daqueles com predomínio de elementos azonais. Isso porque a partir de faixas altimétricas superiores a 1500 metros, em média, os elementos da tropicalidade se atenuam, e, mesmo mediante volumes pluviométricos condizentes com aqueles vigentes nos cinturões tropicais úmidos, o relevo impõe a ocorrência de solos rasos destoantes dos sistemas de transformação pedológica tropicais, bem como 
engendra maior acúmulo de matéria orgânica em função das temperaturas mais baixas. Ainda, barra o avanço da floresta a partir da sucessão altitudinal que impõe à vegetação, associando aos solos imaturos fitofisionomias campestres com similaridades andinas e subtropicais. Claro que a faixa de 1500 metros é naturalmente desprovida de fixidez, mas pode ser tomada como uma referência geral de boa congruência com os processos sucessionais de geoambientes nos domínios montanhosos do Brasil Sudeste, e que varia para níveis altimétricos tanto superiores como inferiores em função de fatores como a orientação das vertentes e a litologia. Em quartzito, por exemplo, campos rupestres eclodem em altitudes consideravelmente inferiores.

Os campos altimontanos do Caparaó se arranjam em mosaicos que integram fitofisionomias herbáceas e arbustivas (figura 5). Ainda que se definam com veemência à montante de hollows suspensos, sua emergência é irregular e por vezes intermediada por nanoflorestas que ocorrem nessas áreas de tensão, bem como nas grotas mais úmidas das cimeiras. Predominam os campos herbáceos, tanto nos compartimentos escarpados como nos patamares de cimeira, onde são quase absolutos, posto que nas altitudes mais extremas o substrato é caracterizado por alta rochosidade, fazendo com que a vegetação assuma um caráter mais esparso em fisionomias eminentemente rupestres, com considerável dominância de gramíneas Poaceae. Os arbustais ocorrem em manchas, sobretudo nas vertentes a sotavento, posto que naquelas orientadas para leste, mais úmidas, o avanço da Floresta Ombrófila Densa ao longo dos vales é bem pronunciado. Indubitavelmente, a sucessão ecológica que define a evolução desses tipos fisionômicos é consideravelmente influenciada pelo fogo, tendo sido encontrados vestígios de paleoincêndios em campo através de fragmentos de carvão enterrados, indicando o caráter imemorial do processo.

Nos segmentos florestados das escarpas o caráter tropical é explícito e realçado pelas luxuriantes fisionomias vegetais que revestem as encostas íngremes. Quanto aos solos, embora de desenvolvimento restrito, são mais espessos, com uma faixa maior de Cambissolos associados a Neossolos que se distribuem de forma mais contínua, exceção feita aos taludes com declives 
extremos talhados sobre free faces. Seu contato com os geossistemas azonais é difuso, havendo áreas de tensão ecológica marcadas pelo definhamento progressivo das florestas visualizáveis nas fisionomias nanoflorestais e nas áreas de floresta aberta com predomínio de candeias (Eremanthus sp).

Nos patamares reafeiçoados pelos quais se define os limites do parque, verifica-se que em parte a vegetação é formada por grupos ecológicos pioneiros, com conspicuidade de embaúbas (Cecropia sp), angicos (Anadenanthera sp), paineiras (Ceiba speciosa), aroeiras (Lithraea sp.) e também candeias (Eremanthus $s p$ ) sinalizando o estágio sucessional, conforme se verifica pela entrada do PARNA Caparaó a partir de Espera Feliz (MG). Presumivelmente, se referem a áreas outrora desflorestadas e que passam por franca restauração ecológica após a criação do parque e consequente inibição dos fatores de alteração. Em demanda às escarpas, a vegetação vai assumindo um caráter mais selvagem com espécies típicas de estágios sucessionais mais avançados, como o cedro (gênero Cedrela), jequitibás (Cariniana sp), palmiteiros (Euterpe sp), jabuticabeiras (Myrciaria sp), etc. Um dado biogeográfico interessante é a presença de Araucaria angustifolia, espécie que teve apenas um indivíduo aferido em campo, e que provavelmente tem ali seu limite setentrional no contexto climatérico atual.

Os contatos abruptos entre os geossistemas se dão tipicamente entre os grupos de fácies definidos em unidades de uso da terra mais específicas. $O$ contato entre as áreas antropizadas e destas com os geossistemas com predomínio de estruturas naturais é acentuadamente abrupto. Perfazem fundamentalmente a classe de fácies dos degraus e patamares reafeiçoados, onde a modalidade de uso da terra predominante é dada pela cafeicultura, que avança até o limite legal do Parque Nacional do Caparaó. Acessoriamente, áreas de pastagem e silvicultura de Eucalyptus partilham da composição estrutural dos geossistemas, além da sede municipal de Alto Caparaó. Os grupos de fácies que aqui se adéquam são definidos a partir de rupturas de declive que indicam reafeiçoamento das escarpas, sugestivamente vinculados a pulsos ascensionais neotectônicos. Comportam mantos de alteração mais espessos, fundamentalmente dados por colúvios pedogeneizados em 
Latossolos associados a Cambissolos, com depósitos de tálus formados por matacões de grandes dimensões que se espraiam até as planícies de terraços do rio Caparaó. Pela vertente leste, a dissecação é mais intensa e apresenta maior tendência à homogeneização, engendrando um maior reafeiçoamento dos patamares inferiores.

A dinâmica dos geossistemas no Caparaó é dada por acentuada lateralidade, com intensa mobilização e retrabalhamento de materiais dos somitais ao sopé do maciço. Intenso coluvionamento é verificado mesmo na presença da cobertura vegetal. Depósitos de tálus são verificáveis em diversas rupturas de declives que atenuam a energia de transporte, sendo que tal processo envolve materiais de diferentes dimensões, desde coberturas argilosas e siltosas até matacões de grandes dimensões, que se aleitam até a planície de inundação e terraços do rio Caparaó que se desenvolvem a oeste da serra, entulhados por materiais, finos e detríticos geneticamente vinculados ao maciço. Nas coberturas argilo-siltosas, em diferentes domínios de encosta, verifica-se a presença de pequenos grãos de quartzo remanescentes (além de alguma muscovita) cujo arranjo geométrico subangular a subarredondado indica pelo menos dois ciclos de transporte e deposição. Também podem ser encontradas lateritas detríticas transportadas em curta distância, tendo como área fonte os setores mais elevados onde os afloramentos são constantes e onde se verificam processos supérgenos de ferruginização sobre os gnaisses.

Quimicamente, as coberturas superficiais são bem uniformes no que se refere à concentração de íons, pH e outras propriedades. Em geral, os solos são predominantemente argilosos, embora ocorram organizações texturais siltosas. Concentrações de bases não muito díspares padronizadas em uma baixa saturação também uniformizam a capacidade de troca catiônica das coberturas pedológicas eminentemente distróficas do topo à base do maciço, bem como a saturação por alumínio, geralmente elevada. Não se verificou assim uma significativa diferenciação geoquímica entre as unidades topomorfológicas, dos interflúvios em direção ao sopé da estrutura que define o Caparaó, o que se explica pela relativa uniformidade mineralógica das rochas que balizam o compartimento. Naturalmente, foi constatado um aumento da 
concentração de matéria orgânica com a altitude em função na atenuação das temperaturas médias, que inibe uma franca decomposição e possibilita uma maior preservação destas substâncias, existentes na forma de turfeiras ou em bolsões de acumulação.

Indubitavelmente, a forte lateralidade é uma característica fundamental no entendimento da dinâmica de sistemas ambientais montanhosos, nos quais a cascata de massa e energia é intensa e coloca em integração intensa os diferentes compartimentos, escalonadamente dispostos, tanto no plano superficial como subsuperficial. Encerram-se assim processos físicos por vezes agudos que circunstancialmente se exasperam diante do controle climático tropical, sobretudo durante os espasmos climáticos que tendem a catalisar a dinâmica das encostas em resposta à saturação das coberturas superficiais diante de altos volumes pluviométricos concentrados. O planejamento dessas áreas quase sempre exaltadas em suas funcionalidades conservacionistas, tal como se verifica no contexto do Caparaó, deve atinar com afinco a tais propriedades, reconhecendo de forma abrangente as especificidades dos ambientes montanhosos, suas formas e processos próprios e o encadeamento destes meios com os compartimentos adjacentes com os quais estabelecem contato, e que normalmente são os receptores dos fluxos superficiais e subsuperficiais advindos dessas áreas mais elevadas, onde a energia do relevo é mais substancial.

\section{CONCLUSÕES}

O plano de informações gerado na escala trabalhada, embora não seja adequado de forma direta ao planejamento ambiental regional, é de grande utilidade para a gestão do Parque Nacional do Caparaó, uma vez que traz a lume os elementos estruturais fundamentais das paisagens adstritas ao seu perímetro e daquelas que circundam o seu entorno direto, e de onde provem os principais e mais recorrentes fatores de ameaça. Muitas unidades de conservação existentes no Brasil tropical atlântico possuem dimensões restritas, até mesmo em função da dinâmica intensiva de uso da terra e da concentração urbano-industrial que dá a tônica da ocupação da fachada 
costeira brasileira. Dessa maneira, é necessária a geração e disponibilização de informações espaciais que estejam organizadas e representadas cartograficamente em escalas sub-regionais, compatíveis com a área destas reservas e operacionalizáveis em seus programas de manejo.

A individualidade geográfica inerente a Serra do Caparaó se revela de forma contundente no contexto regional, e a abordagem geossistêmica firmada nos pressupostos metodológicos trabalhados no âmbito da presente reflexão revelou dados essenciais acerca de sua estrutura e dinâmica. Além da articulação dos componentes zonais e azonais, este topogeócoro congrega tipos de paisagem próprios e de exceção, expressas pelos remanescentes florestais e, sobretudo, pelos disjuntos e sui generis campos altimontanos, bem como paisagens comuns que se fazem dominantes no contexto regional, no caso aquelas que consorciam pastagens e cafeicultura, fundamentalmente. $\mathrm{Na}$ intercace entre os tipos de paisagem raras e de exceção e os tipos de paisagem comuns e de estrutura simples, fica possível estabelecer uma articulação dialógica entre o local e o regional, posto que as tipologias mais comuns figuram como aquelas dominantes na região, pontuada por enclaves de paisagens de aspecto natural remanescentes, que tem no maciço do Caparaó um de seus mais importantes depositários.

Propostas de planejamento coerentes, fundamentadas e exequíveis devem se pautar no levantamento e estudo integrado destas paisagens de exceção em suas relações com o contexto regional. Destacadamente, a oeste do Caparaó localiza-se a estrutura da Serra do Brigadeiro, também portadora de remanescentes florestais e campos altimontanos protegidos em unidade de conservação de proteção integral, ambas separadas por compartimentos intermontanos mais profundamente antropizados, emergindo como imperioso desafio, por exemplo, a reorganização dos mosaicos existentes voltada para o reestabelecimento de conectividades funcionais entre os compartimentos altimontanos e montanhosos. O cumprimento desse desafio passa, necessariamente, por estudos em escala regional voltados para o planejamento ambiental, referenciado em um zoneamento integrado que esteja cimentado em uma base de dados confiável e suficientemente abrangente dos 
aspectos dinâmico-funcionais fundamentais das paisagens existentes, empreitada que tem na abordagem geossistêmica, convictamente, um valioso aporte teórico-metodológico.

\section{REFERÊNCIAS}

ABALAKOV, A. D.; SEDYKH, S. A. Regional-typological study and mapping of geosystems: analysis of the implementation. Geography and Natural Resources, New York, v. 31, p. 317-323, 2010.

AZEVEDO, A. Geografia Física. São Paulo: Companhia Editora Nacional, 1949. 398p.

CUNHA, C. M. L.; MENDES, I. A. Proposta de análise integrada dos elementos físicos da paisagem: uma abordagem geomorfológica. Estudos geográficos, Rio Claro, v. 3, n. 1, p. 111-120, 2005.

DE MARTONNE, E. Problemas morfológicos do Brasil Tropical Atlântico. Revista Brasileira de Geografia, Rio de Janeiro, v. 5, n. 4, p. 532-550, 1943.

FARIA, A. P. Classificação de montanhas pela altura. Revista Brasileira de Geomorfologia, Brasília, v. 6, n. 2, p. 21-18, 2005.

HAASE, G. Medium scale landscape classification in the German Democratic Republic. Landscape Ecology, New York, v. 3, n. 1, p. 29-41, 1989.

HUGGETT, R. J. Geoecology: an evolutionary approach. Routledge: London and New York, 1995. 320p.

ISACHENKO, A. G. Principles of landscape science and Physical Geography Regionalization. Melbourne, 1973. 311p.

IBGE. INSTITUTO BRASILEIRO DE GEOGRAFIA E ESTATÍSTICA. Manual técnico da vegetação brasileira. Série Manuais Técnicos em Geociências, n. 1, Rio de Janeiro, 1992. 
KING, L. C. A Geomorfologia do Brasil Oriental. Revista Brasileira de Geografia. Rio de Janeiro, v. 18, 147-265, 1956.

MINISTÉRIO DAS MINAS E ENERGIA. Projeto Radambrasil. Folha SF-23 Vitória/Rio de Janeiro. Rio de Janeiro, 1983.

NOVO, T. A.; NOCE, C. M.; PEDROSA-SOARES, A. C.; BATISTA, G. A. P. Rochas granulíticas da Suíte Caparaó na região do Pico da Bandeira: embasamento oriental do orógeno Araçuaí. Geonomos, Belo Horizonte, v. 19, n. 2, p. 70-77, 2011.

PONÇANO, W. L; CARNEIRO, C. D. R; BISTRICHI, C. A; ALMEIDA, F. F. M; PRANDINI, F. L. Mapa geomorfológico do estado de São Paulo. Vol. 1. Instituto de Pesquisas Tecnológicas, Divisão de Minas e Geologia Aplicada, 1981. 94p.

PRICE, L. W. Mountains and man. Berkeley: University of California Press, 1981.

RICCOMINI, C. O rift continental do sudeste do Brasil. 1989, São Paulo, 1989. 256p. Tese de Doutorado, Instituto de Geociências, Universidade de São Paulo, São Paulo.

RODRIGUEZ, J. M. M.; SILVA, E. V.; CAVALCANTI, A. P. Geoecologia das paisagens: uma visão geossistêmica da análise ambiental. $3^{\circ}$ ed. Fortaleza: edições UFC, 2010. 222p.

ROGERIE, G. Les montagnes dans la biosphère. Armand Colin: Paris, 1990. $219 p$.

SOCHAVA, V. B. Geography and ecology. Soviet Geography: review and translation. New York, v. 12, n. 5, p. 277-293, 1971.

Paulo, n 16, p. 1-51, 1977.

O Estudo dos Geossistemas. Métodos em Questão. São

Por uma Teoria de Classificação dos Geossistemas da Vida Terrestre. Biogeografia. São Paulo. n. 14, p. 1-24, 1978.

Introducción a la doctrina sobre los geosistemas. Novosibirsk: Nauka, filial de Sibéria, 1978. 318p. (em russo).

VITTE, A. C. A construção da geomorfologia no Brasil. Revista Brasileira de Geomorfologia, Brasília, v. 12, n. 3, p. 91-108, 2011. 